\title{
CURSO DE FORMAÇÃO DOCENTE EM ESPAÇO NÃO FORMAL: RELATO DE EXPERIÊNCIA EM PROJETO DE ENSINO INTERDISCIPLINAR
}

\section{TEACHER TRAINING COURSE IN NON-FORMAL ENVIRONMENT: EXPERIENCE REPORT ON INTERDISCIPLINARY TEACHING PROJECT}

\author{
Tábata Elise Ferreira Cordeiro* \\ Brucce Sanderson Prado de Freitas* \\ Aline Melina Vaz ${ }^{* *}$ \\ Danilo Sasso Augusto***
}

\begin{abstract}
RESUMO: O PEIC (Projeto de Ensino Interdisciplinar Comunitário) é um projeto voluntário que se propõe trabalhar a educação em um ambiente não formal, promovendo a interdisciplinaridade entre as diferentes áreas do conhecimento. Ao contrário de um ensino fragmentado, descontextualizado e hierárquico, o PEIC objetiva o aprendizado significativo dos seus educandos de forma humanizada, contextualizada, horizontal por meio de propostas inovadoras de ensino. Para que esse objetivo seja alcançado os voluntários do PEIC têm se preocupado cada vez mais com a sua formação pedagógica continuada. Esse pensamento é a justificativa para a concepção, planejamento e execução do Curso de Formação para novos voluntários ministrado no início de 2017 e tem o seu relato de experiência descrito e analisado neste artigo.
\end{abstract}

Palavras-chave: Formação de professores; Educação não-formal; Interdisciplinaridade; PEIC.

ABSTRACT: PEIC (Projeto de Ensino Interdisciplinar Comunitário) is a voluntary project that proposes to work on education in a non-formal environment, promoting interdisciplinary between different areas of knowledge. In contrast to fragmented, decontextualized, and hierarchical teaching, PEIC aims at the meaningful learning of its students in a humanized, contextualized, horizontal way, through innovative teaching

* Doutorado em Biologia Comparada pela Universidade de São Paulo (USP), campus Ribeirão Preto. Contato: tabata_elise@hotmail.com

** Mestre em Ensino de Ciências (ênfase Ensino de Biologia) pela Universidade de São Paulo (USP), Campus São Paulo. Contato: bruccesanderson@gmail.com.

*** Doutorado em Psicobiologia pela Universidade de São Paulo (USP), campus Ribeirão Preto. Contato: alinemelinavaz@gmail.com

**** Mestre em Biologia Celular e Molecular pela Universidade de São Paulo (USP), campus Ribeirão Preto. Contato: danilo.sasso.augusto@usp.br 
proposals. For this objective to be achieved, PEIC volunteers have been increasingly concerned with their continued pedagogical training. This thought is the justification for the conception, planning, and execution of the Training Course for new volunteers that was taught in early 2017 and has its experience report described and reflected in this article.

Keywords: Teacher training; Non-formal education; Interdisciplinarity; PEIC.

\section{INTRODUÇÃO}

A pedagogia tradicional conserva em nossa sociedade uma estrutura hierárquica e fragmentada dos saberes. Segundo essa tendência educacional, os conteúdos do ensino referem-se aos conhecimentos e valores sociais acumulados, pré-determinados, sequenciados e transmitidos como verdades imutáveis (LUCKESI, 1991). Nessa perspectiva, o ensino é centrado no professor que transfere aos seus alunos - seres sem luz - conhecimentos a serem memorizados e reproduzidos em provas e testes. O estudante não consegue estabelecer a relação entre aquilo que é "ensinado" e seu cotidiano (FREIRE, 1996), o que pode ser desmotivador e excludente.

A educação popular, desde o início da sua concepção, se opôs a essa ideia de ensino bancário (GADOTTI, 2012). A educação popular como ato político, valoriza o pensamento crítico e prioriza movimentos de transformação da sociedade. Gadotti (2012) argumenta que:

Um dos princípios originários da educação popular tem sido a criação de uma nova epistemologia, baseada no profundo respeito pelo senso comum que trazem os setores populares em sua prática cotidiana, problematizando-o, tratando de descobrir a teoria presente na prática popular, teoria ainda não conhecida pelo povo, problematizando-a também, incorporando-lhe um raciocínio mais rigoroso, científico e unitário. (GADOTTI, 2012, p. 7).

Nesse contexto, a educação pensada para além dos muros da escola é de fundamental importância (JACOBUCCI, 2008; MARANDINO, 2009). A educação em espaços não formais pode se apresentar como uma estratégia que 
contribui - mas não exclui - para o desenvolvimento de habilidades sociais de crianças, jovens e adultos que: estudam ou terminaram os estudos; não tiveram oportunidades para estudar ou, se tiveram, foram excluídos por metodologias e avaliações centradas em conhecimentos e contextos distantes de suas realidades (SPOSITO, 2008; GOHN, 2009).

Para a discussão desse artigo vamos assumir a concepção de que espaços não formais de ensino-aprendizagem existem quando há a intencionalidade dos sujeitos em criar ou buscar determinados objetivos fora da instituição escolar (GOHM, 2009). O ensino em espaços não formais possibilita uma flexibilidade de tempos, espaços, conteúdos, métodos de trabalho (PIVELLI, 2006), habilidades e competências. Essa flexibilidade associada a escolha de temas que estejam diretamente relacionados ao contexto social do aluno e a valorização da interdisciplinaridade no processo de ensinoaprendizagem coloca os estudantes como agentes ativos; sujeitos para intervenção social com o uso dos conhecimentos e ferramentas social e historicamente constituídas no processo de criação do seu ambiente (VYGOTSKY, 1984).

Os espaços não formais de ensino estimulam o prazer em aprender, pois não carregam a mesma formalidade consigo, a obrigatoriedade com metodologias, testes e avaliações tradicionais ainda hoje exigidas da educação escolar formal. A não obrigatoriedade com esses aspectos dos sistemas de ensino possibilita a implementação de uma diversidade metodológica que é, como considera Terci e Rossi (2015), importante para despertar nos estudantes o encantamento, a motivação e a contextualização de saberes. A educação não formal pode ainda estabelecer uma relação professor-aluno mais horizontalizada, pautada em uma intencionalidade de ensino e planejamento dos objetivos pedagógicos que estimulem a participação dos envolvidos no processo de aprendizagem (PRÍNCEPE; DIAMENTE, 2011).

Como destaca Kato (2011), cursinhos e projetos populares, bem como outros espaços não formais de ensino, são ambientes privilegiados de acesso formativo às vivências historicamente restritas à determinada classe hegemônica. Esses espaços são ricos do ponto de vista do intercâmbio de 
ideias, aproximando seus participantes da realidade social e acadêmica a qual estão inseridos. Para Zago (2008), desde de sua gênese na segunda metade dos anos 80 , os cursinhos populares

[...] têm como principal objetivo a democratização do ensino. Esses cursos surgem em um contexto contraditório do sistema educacional que [...] se por um lado ampliou consideravelmente o número de vagas, de outro mantém profundas desigualdades no acesso ao ensino superior. Fazem parte de grupos sociais tradicionalmente excluídos do ensino superior (negros, moradores de bairros populares, egressos de escolas públicas), cuja problemática originou movimentos sociais que reivindicam seu acesso, bem como o fortalecimento da universidade pública. (ZAGO, 2008, p. 151 - 152).

Os cursinhos populares são majoritariamente gratuitos e, quando cobram alguma quantia, destina-se a manutenção da estrutura física, transporte dos voluntários e palestrantes; não possuem propostas pedagógicas unicamente vinculadas à aprovação no vestibular; o corpo docente e administrativo é voluntariado; e não possuem sede fixa, ocupando espaços como escolas, universidade, instituições comunitárias e/ou religiosas (THUN, 2000; OLIVEIRA, 2001), entre outras características que fazem deles contextos específicos de formação.

O presente texto é um relato de experiência sobre a construção e aplicação do Curso de Formação Pedagógica do ano de 2017 para novos voluntários que começaram a integrar o PEIC (Projeto de Ensino Interdisciplinar Comunitário). Apresentaremos este relato dividido em quatro partes: a apresentação do projeto e seus desafios formativos; a construção do formato do curso de formação, com o desenvolvimento das ideias subjacentes à sua elaboração; o relato dos encontros do curso de formação (O que é aprender?; Interdisciplinaridade; O que é ensinar?; Planejamento de aula); e a autoavaliação do trabalho desenvolvido com sugestões sobre o que poderia ser modificado a fim de alcançar os objetivos traçados. Finalizamos este relato com reflexões sobre a formação de voluntários para projetos de ensino com vistas à educação popular e as práticas desenvolvidas no PEIC. 


\section{APRESENTANDO O PEIC}

O PEIC (Projeto de Ensino Interdisciplinar Comunitário) foi criado no ano de 2003 com o desejo de promover um espaço de educação não formal, um local onde diferentes formas de disseminação do conhecimento pudessem ser refletidas por meio da inclusão social e da contextualização dos conteúdos (KATO, 2011). A motivação para a criação do projeto foi a insatisfação de discentes do curso de Ciências Biológicas, da Faculdade de Filosofia, Ciências e Letras, da Universidade de São Paulo, Campus Ribeirão Preto (USP-RP), com a fragmentação do ensino tradicional e o acesso às ideias do livro "O ponto de Mutação" de Fritjof Capra (1982). A ideia inicial do projeto era promover um ensino que valorizasse a integração do saber por meio da interdisciplinaridade e a formação crítica cidadã (CARVALHO, 2008; KATO, 2011).

A história do PEIC pode ser dividida em 3 fases. A primeira fase contempla a fundação do PEIC e sua organização inicial. Os primeiros voluntários, discentes do curso de Ciências Biológicas, criaram um núcleo para discussões das propostas sobre como implementar um projeto educacional comunitário, onde as disciplinas seriam apresentadas em grandes áreas: Ciências Humanas, Ciências Naturais e Ferramentas ${ }^{2}$. Ao final das discussões no núcleo essa dinâmica de ensino-aprendizagem foi abandonada devido à falta de experiência pedagógica dos voluntários (CARVALHO, 2008).

A segunda fase do PEIC, iniciada em 2004, pode ser caracterizada pela implementação do projeto. O PEIC foi estruturado como um cursinho comunitário pré-vestibular com uma proposta interdisciplinar. Voluntários de outros cursos dentro da USP começaram a participar e contribuir com o projeto e a Faculdade de Filosofia, Ciências e Letras entrou com o apoio institucional, cedendo o espaço físico, fornecendo apoio e formação pedagógica (CARVALHO, 2008).

Após a experiência como cursinho popular pré-vestibular, os voluntários sentiram a necessidade de uma reformulação pedagógica e organizacional. $\mathrm{Na}$

\footnotetext{
2 Por ferramentas era entendida a área de estudos que ofereceria recursos de suporte para a compreensão das áreas da ciência. Era composta por matemática, português e inglês (CARVALHO, 2008).
} 
terceira fase do PEIC foi resgatada a estrutura de grandes áreas de conhecimento como forma de organizar as aulas e práticas pedagógicas que retomavam e fortaleciam a proposta de interdisciplinaridade entre áreas, almejada desde o início do projeto. Dessa forma, o PEIC se organizou nas seguintes áreas: Linguagem e Comunicação, Ciências Exatas, Ciências Humanas, Ciências Naturais e Grupo de Apoio Psicológico/Grupo de Orientação Profissional (GAP/GOP), além de uma área administrativa para gerir questões de cunho institucional.

A reestruturação do PEIC contribuiu para o amadurecimento do projeto no sentido de se reconhecer, cada vez mais, como uma proposta alternativa de ensino. Com as discussões que culminaram no primeiro Projeto Político Pedagógico (2018), consolidou-se o objetivo do projeto em

proporcionar ensino de qualidade com visão integrativa, promovendo o desenvolvimento emocional, cultural e social dos alunos que atende, contribuindo para a formação de cidadãos que o possuam uma perspectiva crítica diante da realidade ambiental, cultural e social que os cerca. (PEIC, p. 13).

Com mais de quinze anos de existência, o PEIC está sempre buscando metodologias que promovam o processo de ensino-aprendizagem dos educandos, desenvolvendo competências e habilidades, como o senso crítico, a autonomia, a pró-atividade e o envolvimento sócio-afetivo, além de estimular a curiosidade, a pesquisa e o respeito às diferenças. Na visão dos voluntários do projeto, para que o processo de aprendizagem se consolide, cada novo tema que é discutido precisa ser incorporado às memórias do aluno de forma contextualizada, levando-se em consideração os seus conhecimentos prévios e construindo esse novo conhecimento de forma participativa (PELIZZARI et al., 2002).

O PEIC é um projeto de educação popular sem fins lucrativos. Por projeto de educação popular entende-se que é um espaço não formal de ensino com vistas ao diálogo e vivências entre seus participantes, sem compromisso direto com o ensino voltado ao acesso à universidade pública, assim como outros cursinhos populares (ZAGO, 2008). Para ingressar no projeto o candidato 
precisa ter concluído o ensino fundamental e participar do processo seletivo realizado semestralmente. Os estudantes são, em sua maioria, adolescentes (ainda que haja alguns jovens e adultos) da cidade de Ribeirão Preto e região, provindos das camadas sociais mais populares.

O PEIC possui em comum com outros cursinhos populares da região de Ribeirão Preto: a não remuneração de seus voluntários, com exceção de ajuda com os custos de transporte e materiais didáticos; os voluntários em sua maioria serem estudantes de graduação e pós-graduação, professores de ensino básico e profissionais liberais; a seleção de alunos considera a condição socioeconômica, exigindo a comprovação de renda dos candidatos (KATO, 2011).

O grupo de voluntários é heterogêneo e com motivações de participação distintas: alguns voluntários participam por considerar que contribuem com a sociedade ao oferecer espaço de ensino contextualizado; outros entendem o projeto como um espaço de formação aberto à experimentação didática; e há ainda àqueles que participam do projeto para completar os créditos das atividades curriculares exigidas em seus cursos de graduação. Independente da motivação, os voluntários são acolhidos e contribuem de forma assimétrica no projeto, cada qual com o que possa contribuir. Nesse contexto, a formação dos voluntários tem sido uma questão recorrente, uma vez que as motivações de participação são múltiplas e a não exigência dos voluntários cursarem ou terem cursado Licenciatura tangenciam aspectos pedagógicos do projeto.

Com esses desafios a equipe de voluntários entendeu que precisava se engajar em uma formação pedagógica bem estruturada a fim de atender os objetivos do projeto. Desse interesse e necessidade, várias iniciativas foram pensadas e implementadas ao longo da história do projeto sem uma continuidade até o ano de 2016, quando foi proposta uma nova área: o Grupo de Estudos Pedagógicos (GEP). O GEP tem em vista dois objetivos principais: promover a formação dos voluntários do projeto e auxiliar na efetivação da interdisciplinaridade entre as áreas. Dessa iniciativa, em 2017 foi proposto o curso de formação para novos voluntários. 


\section{O CURSO DE FORMAÇÃO DE NOVOS VOLUNTÁRIOS}

O curso de formação para os novos voluntários do PEIC foi articulado pelos membros do GEP, abordando aspectos teóricos e práticos do fazer docente, com enfoque nas demandas teórico-práticas do projeto. Dessa forma, a escolha dos temas do curso de formação para novos voluntários deveria introduzi-los no contexto das propostas de ensino do PEIC.

Durante as reuniões de planejamento do curso foi discutida a escolha dos temas que seriam abordados durante as aulas e a sua relevância no processo de formação de novos voluntários num ambiente não formal de ensinoaprendizagem. Portanto, os seguintes temas foram escolhidos para serem abordados no primeiro curso de formação de novos voluntários: 1) O que é aprender?; 2) Interdisciplinaridade; 3) O que é ensinar?; e 4) Planejamento de aula.

Esses temas foram pensados levando-se em consideração as futuras experiências que esses novos voluntários experimentariam dentro do PEIC, um ambiente no qual se almeja um processo de ensino-aprendizagem favorecido por diferentes formas de ensinar, fazendo uso de diferentes estratégias pedagógicas e com a paciência de quem acredita que a aprendizagem se concretiza de diferentes formas e momentos para cada indivíduo. Foi escolhido um formato de aula expositivo-dialogada, com a apresentação de alguns conceitos-chaves e discussão livre e uma proposta de atividade/problematização que contribuíssem para que os objetivos das aulas fossem alcançados. As estratégias pedagógicas escolhidas foram uma tentativa de se obter sucesso em uma ideia que pode ser resumida na seguinte sentença: Fazer uma aula no "formato PEIC" para o PEIC. Entendendo que "formato PEIC" representa aulas pouco tradicionais, pouco ortodoxas, que promovem reflexão, aprendizagem e se tornem lembranças agradáveis para quem as vivencia.

Os voluntários do PEIC chegam ao projeto com concepções sobre ensinar e aprender arraigados ao modelo de escola que vivenciaram. Por vezes, reproduzem práticas que enrijecem tempos, espaços, conteúdos e métodos de trabalho, não aproveitando as vantagens formativas que os espaços não formais 
possibilitam (PIVELLI, 2006). Pensando nisso, avaliamos como necessário conversar em nossos encontros sobre concepções de aprender e ensinar.

Reconhecemos, desde o início, "O que é aprender?" e "O que é ensinar?" são perguntas audaciosas, e já adiantamos: nunca tivemos a pretensão de respondê-las de uma forma única. Possivelmente, não tivemos nem a pretensão de, sequer, respondê-las de alguma forma. Mas, compreendemos como essencial, já desde o primeiro dia, primeiro contato, trazer a provocação que nos traz toda boa pergunta. "O que é aprender?" e "O que é ensinar?" nos pareceram essas boas perguntas.

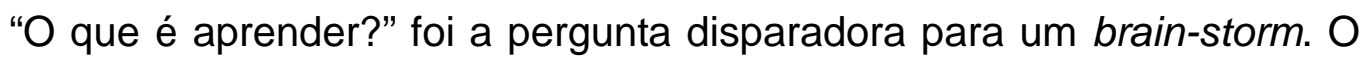
objetivo disso, como descrito no plano de aula (Apêndice A), era provocar nossos voluntários ingressantes, e que essa provocação nos auxiliasse em um processo de desconstrução de ideias tomadas como um consenso entre os indivíduos de que todos sabem o que é aprender e que "aprender" é concebido de forma igual por todos os indivíduos de uma forma geral. Assumimos que esse tipo de premissa, muitas vezes naturalizada entre os envolvidos nos processos educativos, pode dificultar a comunicação entre os pares envolvidos em um processo de aprendizagem. Por isso, antes da apresentação de qualquer ideia sistematizada de algum teórico da Psicologia Educacional era preciso trazer à tona a reflexão do que é o processo de aprendizagem, o que cada um traz de experiência própria sobre o aprender.

Para mediar essas reflexões, sentenças que representavam ideias de cada uma das principais "Teorias de Aprendizagem" (Concepção tradicional, Epistemologia Genética, Sócio-histórica, Behaviorismo, Cognitivismo, Construtivismo) foram distribuídas para cada aluno do curso. Cada um se apresentou brevemente e leu a sua frase em voz alta para os presentes. Após todos se apresentarem foi solicitado que eles se agrupassem de acordo com as semelhanças dos conteúdos das frases. Certamente isso serviu de ocasião para que circulassem na sala, falassem uns com os outros, solicitassem que as frases fossem relidas para que pudessem avaliar melhor suas semelhanças, e interagissem bastante entre si, considerando que se tratava de um primeiro encontro, e nem todos se conheciam. 
Após a organização dos grupos, algumas frases "sobraram" (propositalmente, havia mais frases que alunos presentes), e elas foram "leiloadas", isto é, os grupos que julgaram que elas faziam sentido dentro do seu escopo de frases as tomaram para si. Dado o pouco tempo disponível para abordar várias teorias de aprendizagem, que geralmente são trabalhadas ao longo de todo um semestre letivo nos cursos de licenciatura, a ideia de utilizar as frases referentes a cada autor/teoria foi uma estratégia de colocar os alunos em contato com esses conteúdos já desde o início da formação, ainda que de uma forma pouco sistematizada.

Esta atividade foi chamada de "Quebra-cabeça Epistemológico", justamente para brincar com a ideia de "encaixar ideias" e dar um sentido para elas. Havia um "gabarito", é claro, considerando que aquelas frases foram retiradas dos materiais referentes a cada teoria da aprendizagem, logo havia as "frases tradicionais", as "frases behavioristas", as "frases construtivistas", e assim por diante. Entretanto, sabemos (e acreditamos) que muitas dessas teorias não são dicotômicas e muitas vezes são semelhantes ou podem ser vistas como complementares entre si. Portanto, importava muito mais o sentido atribuído ao conjunto de frases que cada grupo conseguiu dar do que "acertar os autores" propriamente ditos.

Depois de uma discussão sobre os conteúdos das frases e a forma como os alunos se organizarem, apresentando os argumentos que justificavam seu agrupamento, já encaminhando o encontro para o final, houve uma apresentação mais sistematizada de cada Teoria de Aprendizagem. Nesta apresentação tentou-se aproveitar a experiência que havia acabado de ser vivida entre os alunos para ilustrar as principais ideias de cada autor. Foi uma apresentação breve, cujo objetivo foi uma tentativa de formalizar e sistematizar o conteúdo que havia sido discutido durante a atividade.

Os participantes relataram que a exposição mais sistematizada dos conteúdos foi rápida demais para que eles pudessem se apropriar, ainda que superficialmente, de todas as teorias. Entretanto, os relatos foram positivos em relação à primeira parte do encontro, a atividade do "Quebra-cabeça Epistemológico". Essas impressões e também o conteúdo da discussão de 
fechamento desta atividade nos levam a perceber que alcançamos o objetivo geral de "Desconstruir a perspectiva tradicional de educação, reconhecendo a existência de diferentes concepções sobre o processo de aprendizagem e discriminar quais concepções estão mais alinhadas à proposta pedagógica do PEIC.”.

Dando continuidade à discussão, concordamos que a estrutura de ensino tradicional que ainda vemos nas escolas é antiquado, opressor e fragmentado. A fragmentação das disciplinas, e o peso que algumas possuem em detrimento de outras, contribui para uma falsa sensação de que os problemas de nossa sociedade podem ser resolvidos com conhecimentos destituídos de contexto e desprovidos da experiência daqueles que os vivenciam. Concordamos que os problemas do cotidiano são históricos, circunscritos à realidades plurais. Para as questões da vida, o conhecimento não pode ter barreiras, hierarquias e pré-requisitos.

Pensando nisso, ao longo do segundo encontro (Apêndice B) os participantes envolveram-se em conversas sobre os temas relacionados à interdisciplinaridade: a confusão no emprego dos diferentes termos relacionados à interdisciplinaridade, a importância de se usar essa abordagem no processo de ensino-aprendizagem e como planejar e executar um projeto pedagógico interdisciplinar em sala de aula.

A interdisciplinaridade surge no século XX como um esforço de superar o movimento de especialização da ciência e a fragmentação do conhecimento em diversas áreas de estudo e pesquisa (FAZENDA, 2003), estabelecendo entre as disciplinas uma relação de comunicação recíproca onde os diferentes saberes são confrontados em busca de um saber unificado, com transferência de conceitos, problemas e métodos (POMBO, 2005).

$\mathrm{Na}$ interdisciplinaridade escolar, noções, finalidades, habilidades e técnicas visam favorecer, sobretudo, o processo de aprendizagem, respeitando os saberes dos alunos e sua integração (FAZENDA, 2008). O curso de formação para novos voluntários teve a intenção de despertar nos seus participantes essa visão. Trabalhar a interdisciplinaridade requer dos voluntários a intencionalidade, o estabelecimento de ligações de interdependência, de convergência e de 
complementaridade entre as diferentes matérias escolares e daqueles que participam das situações de ensino. Romper com a prática pedagógica vigente é um grande desafio e uma inovação. No ambiente de promoção do ensino, o enfoque interdisciplinar mostra que o conhecimento é heterogêneo e não tem fronteiras. Essa visão permite que professores e estudantes se tornem indivíduos mais críticos e criativos, atribuindo maior significado e sentido aos conteúdos aprendidos (THIESEN, 2008).

Pensando no público-alvo do PEIC, a interdisciplinaridade se torna importante porque consiste em identificar problemas relacionados ao seu cotidiano, apresentando as explicações e previsões para esses problemas (ARAÚJO; ALVES, 2014). Para isso, deve ser considerado que os sujeitos possuem experiências múltiplas e visões múltiplas sobre os assuntos e que, a interdisciplinaridade vai contemplar, agregar e incluir, aquilo que historicamente foi excluído, sem fazer juízo de valor, tornando o ambiente de educação popular um espaço de acolhida. Dessa forma, a interdisciplinaridade leva o aluno a ser protagonista da própria história, personalizando-o e humanizando-o, numa relação de interdependência com a sociedade, dando-lhe, sobretudo, a capacidade crítica no confronto da cultura dominante e opressora, por meio de escolhas precisas e responsáveis para a sua libertação e para a transformação da realidade (TARDIF; RAYMOND, 2000).

Durante o encontro muitas experiências dos tempos de escola foram relatadas e relacionadas ao tema. Infelizmente, a maioria dos relatos foram negativos e salientaram o quanto se perde no processo de ensino-aprendizagem quando não se estabelece relações entre as diferentes áreas do conhecimento. Esses relatos refletem diretamente as concepções desses indivíduos sobre quais posturas, métodos, teorias de aprendizagem, entre outros, são positivos e negativos dentro do contexto de sala de aula. Segundo Tardif e Raymond (2000)

[...] o "saber-ensinar", na medida em que exige conhecimentos de vida, saberes personalizados, competências que dependem da personalidade dos atores, de seu saber-fazer pessoal, tem suas origens na história de vida familiar e escolar dos professores de profissão. (TARDIF; RAYMOND, 2000, p. 223). 
Para o segundo encontro do curso de formação propomos como atividade prática a elaboração de uma proposta de Semana Temática para o PEIC, foi o momento de fechamento de ideias e, ao mesmo tempo, uma imersão na filosofia de ensino do PEIC. Todos participaram e colaboraram nos seus grupos para a proposição de um tema e do encadeamento da proposta da Semana Temática ${ }^{3}$.

A partir da atividade prática do encontro pudemos discutir pontos positivos e negativos das propostas apresentadas. Os temas propostos refletiram as preferências pessoais de quem as propôs e, apesar dessas preferências pessoais, os objetivos e justificativas que estavam atrelados às propostas de semana temática eram bastante condizentes com a importância de abordar esses temas em sala de aula. A forma como os temas seriam abordados em cada área também foi um ponto positivo, pois era entremeada por propostas de atividades inovadoras que destacavam reflexões críticas e a inserção do tema no cotidiano de um indivíduo.

A promoção da interdisciplinaridade foi uma dificuldade percebida e compartilhada por todos durante a atividade. Isso acontece, porque os métodos de ensino tradicional não valorizam a interdisciplinaridade e as nossas memórias escolares possuem raras experiências de atividades pautadas no diálogo interdisciplinar. Essa história de vida é importante e se destaca no seu saberensinar, suas vivências como aluno e posteriormente como docente (TARDIF; RAYMOND, 2000).

A melhor forma de desenvolver uma prática interdisciplinar é praticando. Essa é uma dificuldade que foi colocada durante o curso e sempre é discutida no PEIC. Sobre a interdisciplinaridade, Fazenda (1979, p. 10) considera que deva ser uma "relação de reciprocidade, de mutualidade que pressupõe uma atitude diferente a ser assumida diante do problema de conhecimento, ou seja, é a substituição de uma concepção fragmentária para unitária do ser humano"

\footnotetext{
${ }^{3}$ A Semana Temática surgiu como proposta para a promoção da interdisciplinaridade em 2016, como mais uma tentativa de incentivar o diálogo entre os voluntários do PEIC das diferentes áreas e que, dessa forma, trabalhassem juntos para propor formas de se alcançar um processo de ensino-aprendizado efetivo. Durante a Semana Temática, as diferentes áreas trabalham conjuntamente um mesmo tema.
} 
(FAZENDA, 1979, p. 10). Como voluntários do PEIC, entendemos que a interdisciplinaridade só é possível de ser alcançada por meio de uma construção de processos de ensino-aprendizagem coletiva, compartilhada e dialogada, buscando objetivos comuns a todas as áreas de conhecimento. Os objetivos de uma Semana Temática só são atingidos se os seus participantes, docentes e discentes perceberem que o conhecimento de um determinado tema não é provido de forma isolada e fragmentada e que a construção desse conhecimento se dá de forma continuada e com justaposição de diversos domínios do conhecimento (FRANCO, 1997).

O terceiro encontro de formação de novos voluntários (Apêndice $C$ ) relacionou as atividades práticas discutidas no encontro anterior com as teorias de aprendizagem. O pressuposto teórico do qual partimos é de que não há ensino sem aprendizagem (FREIRE, 1996). Por isso, é imprescindível compreender o que é a aprendizagem e qual a relação dela com os elementos culturais acumulados historicamente (VYGOTSKY, 1984).

Inicialmente foi questionado aos participantes o que eles compreendiam por ensinar. As concepções foram anotadas na lousa. A ideia "ensinar é transferir conhecimento" foi a mais frequente, havendo ainda a percepção de que "ensinar é fazer os outros a construir algo", como se ensinar fosse a transmissão de processos e protocolos às outras pessoas.

Em seguida, foi solicitado a eles que retomassem o material produzido na aula anterior (sobre interdisciplinaridade) e escolhessem um dos objetivos específicos dentre os temas propostos, bem como descrevessem como fariam para ensinar um grupo de alunos, de modo a alcançar aquele determinado objetivo. Esta atividade foi proposta em pequenos grupos e após todos terem finalizado, as ideias foram apresentadas.

O momento de apresentação também foi de sistematização de conceitos-chaves referentes ao processo de ensino-aprendizagem. Ao apresentar, os voluntários colocaram em destaque quais recursos e de que maneira eles ensinariam. Em conversa foi diferenciado o que é um recurso didático, uma estratégia didática e uma abordagem de ensino. 
Considerando esses pontos, recurso didático ou ferramenta de ensino foi entendido como os objetos que utilizamos para mediar o processo de ensinoaprendizagem (VYGOTSKY, 1984). Os recursos de ensino estão mais próximos de uma ideia material, ainda que não se reduza apenas a descrição da utilização de objetos físicos, na medida em que uma poesia pode ser entendida como um recurso de ensino.

A ideia de estratégia foi compreendida pelos voluntários como o "como fazer" um programa, um conjunto de regras a se seguir, adequando-se ao conteúdo e ao objetivo proposto para aquela aula. Foi questionado se em uma aula tudo pode ser previsto a priori. Os participantes responderam que não. Por meio de uma conversa diferenciamos o método de estratégia. Método seriam as regras rígidas a se seguir e a estratégia uma busca incessante para reunir informações colhidas durante o percurso (MORIN, 2003). No contexto do PEIC, demanda-se estratégia, visto que ao fazer as aulas consideramos os alunos, o que ocasiona desvios em relação ao planejamento inicial das aulas.

A abordagem diz mais respeito ao professor, a sua concepção de pessoa, do que é ensino e aprendizagem, o que refletirá na complexidade de sua atuação ao utilizar diferentes recursos e estratégias de ensino. A abordagem do professor pode ser observada nas decisões que ele toma na hora da aula, nas adaptações que ele faz no seu planejamento anterior. Se trata da relação entre a ação do professor em sala de aula e a(s) teoria(s) de aprendizagem na(s) qual(is) ele consciente ou inconscientemente se fundamenta. Por isso, a depender da(s) sua(s) concepção(ões) de aprendizagem, sua abordagem em sala pode prever práticas flexíveis ou estruturadas em relação ao seu planejamento.

Partindo da fala dos participantes, diferenciamos esses três aspectos que compõem o processo de ensino e aprendizagem, na medida em que reconhecer esses elementos é imprescindível para que o professor tenha consciência de seu trabalho e avalie a sua prática profissional de maneira a identificar o que promove o sucesso ou o fracasso de sua aula.

No final do encontro foi questionado aos participantes: "O que buscamos ensinar para vocês?". Os participantes relataram que, naquele momento, fazer 
aulas parecia mais complexo do que imaginavam, principalmente àqueles que eram oriundos de cursos de bacharelado. Alguns relataram que a maior dificuldade seria adaptar o planejamento e outros atender a diversidade de formas de pensar dos educandos.

O encontro foi finalizado com uma conversa sobre a importância de ouvir o aluno, habilidade que poderiam desenvolver no contexto do PEIC. Destacamos que ensinar como "transmitir conteúdos" reforça o status quo da visão excludente de educação vivenciada pelos alunos do PEIC na educação formal, sendo assim necessário repensar, enquanto futuros voluntários, maneiras de incluir e constituir espaços assimétricos de aprendizagem em que cada aluno pudesse participar a partir do que sabe, conhece e experencia, ensinando e aprendendo mutuamente. Convidamos os participantes do Curso a abandonar a ideia de transmissão de conteúdos; a pensar que ensinar e aprender são processos indissociáveis, pois "Quem ensina aprende ao ensinar e quem aprende ensina ao aprender" (FREIRE, 1996, p. 25).

O quarto encontro encerrou o Curso de Formação para novos voluntários do PEIC. O objetivo geral deste encontro foi "entender os aspectos teóricopráticos associados ao planejamento de aula". Para tal, entendemos planejamento como:

[...] um instrumento direcional de todo o processo educacional, [...] indica as prioridades básicas, ordena e determina todos os recursos e meios necessários para a consecução de grandes finalidades, metas e objetivos da educação. (MENEGOLLA; SANT'ANNA, 2001, p. 40).

Imaginávamos, com essa organização, que o futuro voluntário do projeto, percebesse a importância de um bom planejamento de aula. O encontro foi dividido em quatro momentos (Apêndice D).

No primeiro momento aconteceu uma troca de experiências relacionadas a necessidade de se realizar planejamentos em diferentes momentos da vida. Nesse ponto foram essenciais a abertura e a participação de todos. Foram narradas experiências de gêneros variados com dois temas mais recorrentes: apresentações acadêmicas durante a formação escolar ou ensino 
superior e apresentações artísticas envolvendo escolhas de repertório, ensaios e execução. Também foram relatados planejamentos de festas, viagens e de eventos cotidianos.

Com os relatos das diferentes experiências sobre o ato de planejar, a discussão foi conduzida para compreender o porquê de o planejamento se fazer tão importante na vida do ser humano. Os participantes refletiram que o percurso entre o surgimento de uma ideia e a sua realização muitas vezes exige um esforço para se entender os processos e os riscos para pôr essa ideia em prática. Baffi (2002) apresentou a atual discussão que envolve o conceito de planejamento e o seu uso na prática do ensino. No encontro essa discussão inicial foi um norte para a pergunta que se seguiu: se temos que nos planejar cotidianamente, por que não fazemos o mesmo para o processo de ensinoaprendizagem?

Depois da contextualização sobre a importância do planejamento no nosso dia a dia, a conversa centralizou-se no planejamento no contexto da educação popular. O processo de ensino e aprendizagem precisa estabelecer uma relação intencional entre os conteúdos e as experiências dos atores envolvidos. O planejamento dos objetivos pedagógicos dá esse respaldo (PRÍNCIPE; DIAMENTE, 2011), auxiliando os voluntários a pensar quais os elementos são importantes para planejar uma aula contextualizada e interdisciplinar. Pode existir flexibilidade de tempo, espaços, conteúdos e metodologias de trabalho, mas o plano de aula norteia a condução das discussões, atividades, encaminhamentos e conclusões das aulas.

Foram apresentados conceitos norteadores como planejamento, plano de curso, plano de ensino e plano de aula, o último sendo destrinchado de forma expositiva-dialogada. A maioria dos presentes não tinha tido contato prévio com um plano de aula e a forma de elaborá-lo. Por esse motivo foram discutidos os pontos essenciais que fazem parte de um plano de aula: tema, objetivos, metodologias, avaliação e bibliografia (TAKAHASHI; FERNANDES, 2004).

Alguns participantes relataram que em suas trajetórias escolares foram capazes de perceber os benefícios de um bom planejamento de aula para 0 processo de ensino-aprendizagem. Esses relatos se concentraram nas 
experiências relacionadas com o desenvolvimento dos objetivos e as propostas de avaliação do plano de aula. Os objetivos chamaram atenção principalmente quanto à elaboração dos objetivos em conceituais, atitudinais e procedimentais (ZABALA, 1998). Os participantes já vinham refletindo sobre objetivos de aula desde o segundo encontro, e a proposta de planejamento de uma Semana Temática os preparou para entender e construir um plano de aula. Os participantes chegaram à conclusão de que a formulação dos objetivos de aula é importante para organizar conceitos, procedimentos e atitudes que serão abordados, sendo como um fio condutor para a escolha de métodos e formas de avaliação. Essa conclusão se assemelha com o que Takahashi e Fernandes (2004) argumentaram sobre a operacionalização da formulação dos objetivos de uma aula.

A avaliação então foi o segundo tópico que mais chamou atenção, principalmente em função da sua característica "traumática". Muitos participantes compartilharam experiências sobre as suas reações quando se depararam com propostas de avaliação punitivas ou levianas. Retomando a discussão de Tardif e Raymond (2000), essas experiências podem ser um elemento motivador para a reflexão sobre os desafios e práticas de uma avaliação de qualidade (SANTOS; PINTO, 2018). O terceiro momento do encontro envolveu colocar em prática os conceitos e práticas que foram discutidos até o momento. Os participantes foram convidados a elaborar planos de aulas em grupos (os mesmos grupos que já estavam trabalhando juntos desde o segundo encontro) para a Semana Temática. Eles tinham que levar em consideração os conceitos discutidos sobre objetivos de aula.

No quarto momento, os grupos apresentaram seus planos de aula aos demais participantes e discutiram a efetividade das aulas planejadas e os seus aspectos positivos e negativos. Esse momento permitiu ver, nos participantes, uma apropriação dos objetivos do encontro, no que se refere à construção de planos de aula. 


\section{REFLEXÕES SOBRE O CURSO DE FORMAÇÃO}

O curso de formação para novos voluntários do PEIC foi pensado e aplicado pela primeira vez em 2017, como foi apresentado neste relato de experiência. Todos os voluntários responsáveis por esse momento de formação tinham menos de um ano de vivência no projeto e isso refletiu na forma como o curso foi pensado, planejado e executado.

Com o intuito de contemplar as diferentes formas de ensinoaprendizagem presentes no PEIC, os membros do GEP buscaram abordar referenciais e técnicas de ensino, o que ocasionou excesso de objetivos a serem alcançados em um curto espaço de tempo.

Cada integrante do GEP possuía trajetórias formativas distintas. Ao elencarem o que consideravam importante para o curso, eles se fundamentaram em referências que aprenderam em seus próprios cursos de formação, o que conferiu ao curso um viés academicista, teórico e que desconsiderou, em alguns momentos do curso, o contexto do projeto.

A história e a atuação do PEIC também devem ser considerados no contexto do curso de formação para novos voluntários. Mesmo com mais de 15 anos de existência o PEIC percorreu essa trajetória e se desenvolveu como projeto de ensino sem uma unidade teórico-metodológica e uma identidade política que fosse conhecida e consentida por todos os membros voluntários. As motivações para se estar no projeto, as visões de sociedade e as concepções de ensino e aprendizagem eram múltiplas. Isso, aliado à rotatividade dos voluntários, refletiu na ausência de um eixo norteador ao projeto e, consequentemente, ao curso de formação.

Em 2018, o Projeto Político Pedagógico do PEIC foi elaborado com o intuito de iniciar o registro das concepções do projeto, assim como o perfil dos seus voluntários e os seus objetivos. A partir do momento em que os voluntários delinearam os objetivos do PEIC, novas edições do curso de formação para novos voluntários puderam ser contempladas com ações que visam atender as demandas acima apresentadas. 
Apesar do exposto, o curso de formação foi uma oportunidade para que os participantes conhecessem o PEIC. Nas palavras de uma participante, "Ajudou a entender como ele funciona". Para alguns participantes o curso de formação também teve um caráter de interação com o "modo de pensar PEIC". Esses relatos se confirmaram também com a observação do maior engajamento dos participantes do curso de formação nos momentos em que eles se envolveram com aspectos práticos dos encontros, como a apresentação e elaboração dos planos de aula e materiais utilizados nas aulas do PEIC.

O curso de formação conduziu os membros do GEP e os voluntários a questionamentos importantes para a continuação do projeto. Como garantir que aquilo que é aprendido nas práticas pedagógicas do PEIC seja compreendido e aperfeiçoado pelos novos voluntários? Como constituir uma linha metodológica que considere a contribuição dos voluntários com diferentes formações? Como articular diferentes interesses e motivações dos voluntários? Essas e outras questões foram pautas de reuniões posteriores no projeto.

Compreendemos que ao propor as atividades de ensino, os voluntários do PEIC questionam práticas que promovem a exclusão dos sujeitos, uma vez que as aulas são planejadas com vistas a criação de espaços de participação. A semana temática é um exemplo disso: a escolha do tema partindo da realidade social e do interesse dos alunos; a contribuição de várias áreas do conhecimento com olhar multifocal sobre um mesmo fenômeno; a criação de espaços em que os alunos levantam e testam hipóteses; o estímulo a momentos de conversas com o intuito de definir a tomada de decisão conjunta; a elaboração de propostas de intervenção; e a sistematização e conclusão de todo o processo. Hoje ponderamos que o curso deveria abordar esses elementos e relacioná-los com as questões relativas à educação popular, à formação crítica e à democratização do ensino.

O Curso de Formação para novos voluntários entrou oficialmente para o calendário de atividades do PEIC, sendo oferecido a todos que desejam ingressar no projeto. A cada ano o curso é repensado e reformulado para introduzir à prática pedagógica do PEIC contribuições das pessoas que atuam ou já atuaram no projeto. 
Temos a expectativa de que novas iniciativas de formação pedagógica sejam implementadas e praticadas de forma contínua dentro do PEIC, levando em consideração as demandas que surgem entre os voluntários e as suas práticas docentes. Esperamos também que o presente relato de nossa experiência possa ser útil, em alguma medida, na formação de novos educadores para além "dos muros do PEIC".

\section{REFERÊNCIAS}

ARAÚJO, Rafaele Rodrigues de; ALVES, Cristiane da Cunha. Na busca da Interdisciplinaridade: Percepções sobre a formação inicial de professores de Ciências da Natureza. Ciência e Natureza, Santa Maria, v. 36, n. 3, 2014.

BAFFI, Maria Adelia Teixeira. O planejamento em educação: revisando conceitos para mudar concepções e práticas. Petrópolis: FE/UCP, 2002.

CAPRA, Fritjof. O Ponto de Mutação. São Paulo: Cultrix, 1982.

CARVALHO, Sibila. "PEIC: de um ponto de mutação à diversidade cultural". Fecunda, Ribeirão Preto, 2008. Disponível em: $<$ https://biofecunda.wordpress.com/2008/10/10/peic-de-um-ponto-de-mutacaoa-diversidade-cultural/>

FAZENDA, Ivani Catarina Arantes (Org.). Integração e interdisciplinaridade no ensino brasileiro: efetividade ou ideologia. 4. ed. São Paulo: Edições Loyola, 1996(1979).

FAZENDA, Ivani Catarina Arantes (Org.). Interdisciplinaridade: qual o sentido? São Paulo: Paulus, 2003.

FAZENDA, Ivani Catarina Arantes (Org.). O que é interdisciplinaridade? São Paulo: Cortez, 2008.

FRANCO, Angela. Metodologia de Ensino. Didática. Belo Horizonte: Lê, 1997.

FREIRE, Paulo. Pedagogia da autonomia. Saberes necessários à prática educativa. São Paulo: Paz e Terra, 1996.

GADOTTI, Moacir. Educação Popular, Educação Social, Educação Comunitária: conceitos e práticas diversas, cimentadas por uma causa comum. Revista Diálogos: pesquisa em extensão universitária. IV Congresso Internacional de Pedagogia Social: domínio epistemológico. Brasília, v.18, n.1, 2012. 
GOHN, Maria da Glória. Educação não-formal, educador(a) social e projetos sociais de inclusão social. Revista Meta: Avaliação, Rio de Janeiro, v. 1, n. 1, 2009.

JACOBUCCI, Daniela Franco Carvalho. Contribuições dos espaços não-formais de educação para a formação da cultura científica. Em extensão, Uberlândia, v. 7, 2008.

KATO, Danilo Seithi. O Papel de cursinhos populares nos acessos e mudanças de perspectivas de seus participantes. Cadernos CIMEAC, Ribeirão Preto, v. 1, n. 1, 2011.

LUCKESI, Cipriano Carlo. Filosofia da educação. São Paulo: Cortez, 1991.

MARANDINO, Martha. Museus de ciências, coleções e educação: relações necessárias.

Museologia e Patrimônio, Rio de Janeiro, v. 2, n. 2, 2009.

MENEGOLLA, Maximiliano; SANT'ANNA,Ilza Martins. Por que Planejar? Como Planejar? Currículo e Área-Aula. Petrópolis: Vozes, 2001.

MORIN, Edgar. A cabeça bem-feita: repensar a reforma, reformar o pensamento. Rio de Janeiro: Bertrand Brasil, 2003.

OLIVEIRA, E. S. Diferentes sujeitos e novas abordagens da educação popular urbana. 155 f. Dissertação (Mestrado em Educação) - Faculdade de Educação da Universidade Federal Fluminense, Niterói, 2001.

PELIZZARI, Adriana et al. Teoria da aprendizagem significativa segundo Ausubel. Revista PEC, Curitiba, v. 2, n. 1, 2002.

PIVELLI, S. Análise do potencial pedagógico de espaços não-formais de ensino para o desenvolvimento da temática da biodiversidade e sua conservação. Dissertação (Mestrado em Educação) - Faculdade de Educação, Universidade de São Paulo, São Paulo, 2006.

POMBO, Olga. Interdisciplinaridade e integração dos saberes. Linc em Revista, Rio de Janeiro, v. 1, n. 1, 2005.

PRÍNCEPE, Lisandra Marisa; DIAMENTE, Juliana. Desmistificando a educação não-formal. Revista Acadêmica Eletrônica Sumaré. v. 1, 2011.

PROJETO DE ENSINO INTERDISCIPLINAR COMUNITÁRIO. Projeto Político Pedagógico. 2018.

SANTOS, Leonor; PINTO, Jorge. Ensino de conteúdos escolares: a avaliação como fator estruturante. In F. Veiga (Coord.), $\mathbf{O}$ Ensino como fator de envolvimento numa escola para todos. Lisboa: Climepsi Editores, 2018. p. 503-539. 
SPOSITO, Marilia Pontes. Juventude e educação: interações entre a educação escolar e a educação não-formal. Educação e Realidade, Porto Alegre, v. 33, n. 2, 2008.

TAKAHASHI, Regina Toshie; FERNANDES, Maria de Fátima Prado. Plano de aula: conceitos e metodologia. Acta Paulista de Enfermagem, São Paulo, v. 17, n. 1, 2004.

TARDIF, Maurice; RAYMOND, Danielle. Saberes, tempo e aprendizagem do trabalho no magistério. Educação \& Sociedade, Campinas, v. 21, n. 73, 2000. p. 209-244.

TERCI, Daniela Brotto Lopes; ROSSI, Adriana Vitorino. Dinâmicas de ensino e aprendizagem em espaços não formais. In: X Encontro Nacional de Pesquisa em Educação em Ciências, Águas de Lindóia, 2015.

THIESEN, Juares da Silva. A interdisciplinaridade como um movimento articulador no processo ensino-aprendizagem. Revista Brasileira de Educação, v. 13, n. 39, 2008.

THUN, Carmo. Pré-vestibular público e gratuito: 0 acesso de trabalhadores à universidade pública. $185 \mathrm{f}$. Dissertação (Mestrado em Educação) - Centro de Ciências da Educação da Universidade Federal de Santa Catarina, Florianópolis, 2000.

VYGOTSKY, Lev Semenovich. A formação social da mente. São Paulo, Martins Fontes, 1984.

ZABALA, Antoni. A prática educativa: Como ensinar. Porto Alegre: Artmed, 1998.

ZAGO, Nadir. Cursos pré-vestibulares: limites e perspectivas. Perspectiva, Florianópolis, v. 26, n. 1, 2008.

Recebido em: 26/02/2021

Aprovado em: 13/09/2021 
APÊNDICE A - Plano de aula do primeiro encontro do curso de formação para novos voluntários do PEIC.

1) Assunto/Conteúdo: Teorias de aprendizagem

2) Objetivo

a) Geral: Desconstruir a perspectiva tradicional de educação, reconhecendo a existência de diferentes concepções sobre o processo de aprendizagem e discriminar quais concepções estão mais alinhadas à proposta pedagógica do PEIC.

b) Específico

- Discriminar posições tradicionais de educação em contraste com outras posições em que há mais protagonismo do educando;

- Compreender a aprendizagem como um fenômeno complexo;

- Entender, ainda que superficialmente, as concepções do que é aprender sob a ótica das principais teorias de aprendizagem (Epistemologia Genética, Sócio-histórica, Behaviorismo, Cognitivismo, Construtivismo) propostas por diferentes autores (Piaget, Vygotsky, Skinner, Ausubel);

- Identificar as principais diferenças entre essas propostas;

- Perceber que a forma de conceber o processo de aprendizagem influencia diretamente na forma como se concebe a educação;

- Identificar quais das teorias apresentadas embasam a aula que acabaram de ter, e que por isso estão mais alinhadas à proposta pedagógica do PEIC.

3) Duração: $2 \mathrm{~h}$ e $30 \mathrm{~min}$ (intervalo de $\pm 30 \mathrm{~min}$ )

4) Metodologia: Recursos e atividades

- Brain-storm: aprender, conceitos dos alunos (10 $\mathbf{~ m i n ) ; ~}$

- Divisão em pequenos grupos: "Quebra-cabeça epistemológico". Os alunos receberão várias frases relativas à contextos que descrevem as diferentes perspectivas teóricas sobre aprendizagem. Deverão discutir seus significados e em seguida organizá-las de acordo com o seu conteúdo subjacente sobre aprendizagem (agrupando semelhantes e 
separando os diferentes). Organizar as ideias numa folha, dar títulos para cada divisão (20 min);

- Compartilhando as ideias: leitura das frases que cada grupo recebeu e apresentação da organização que propuseram, com suas justificativas para aquelas escolhas, estabelecendo as relações com as primeiras exposições no brain-storm (30 min);

- Apresentação expositivo-dialogada, apresentando e sistematizando as teorias psicológicas sobre aprendizagem (40 min);

- Avaliação (20 min);

- Explicação sobre o processo seletivo, esclarecimento de dúvidas (30 $\min )$.

\section{5) Avaliação}

Tendo acesso ao plano da aula que acabaram de participar, e tendo-a experenciado, pergunta-se: quais abordagens teóricas dão subsídios para a aula que acabaram de participar?

6) Bibliografia

AQUINO, Julio Groppa (Org.) Indisciplina na escola: alternativas teóricas e práticas. São Paulo: Summus, 1996.

(org.) Erro e fracasso na escola: alternativas teóricas e práticas. São Paulo: Summus, 1997.

BORUCHOVITCH, Evely. Inteligência e motivação: perspectivas atuais. In: BORUCHOVITCH, Eely. \& BZUNECK, José Aloyseo (Orgs.) A Motivação do Aluno: Contribuições da Psicologia Contemporânea. Petrópolis: Vozes, 2001.

CARRETERO, Mario. Construtivismo e Educação. Porto Alegre: Artes Médicas, 1997.

CARVALHO, José Sergio Fonseca de. Construtivismo: uma pedagogia esquecida da escola. Porto Alegre: Artes Médicas, 2001.

LA TAILlE, Yves.; OLIVEIRA, Marta Kohl de; DANTAS, Heloysa. Piaget, Vygotsky, Wallon: teorias psicogenéticas em discussão. São Paulo: Summus, 1992.

OLIVEIRA, Marta Kohl de. Vygotsky - aprendizado e desenvolvimento: um processo sócio-histórico. São Paulo: Ed. Scipione, 1995. 
OLIVEIRA, Marta Kohl de et al. (orgs) Psicologia, Educação e as Temáticas da Vida Contemporânea. São Paulo: Ed. Moderna, 2002.

PIAGET, Jean. 0 tempo e o desenvolvimento intelectual da criança. In: Piaget, J. Problemas de psicologia genética. Abril cultural, 1978 (os pensadores).

SKINNER, Burrhus Frederic. Sobre o behaviorismo. São Paulo: Cultrix, 1974.

TANAMACHI, Elenita de Rício; PROENÇA, Marilene; ROCHA, Maria Lopes.(orgs.). Psicologia e Educação. São Paulo: Casa do Psicólogo, 2000.

VYGOTSKY, Lev Semenovich. A formação social da mente. São Paulo, Martins Fontes, 1984.

WITTER, Geraldina Porto; LOMÔNACO, José Fernando Bitencourt. Psicologia da Aprendizagem. Temas Básicos de Psicologia. São Paulo: EPU, 1984. 
APÊNDICE B - Plano de aula do segundo encontro do curso de formação para novos voluntários do PEIC.

1) Assunto/Conteúdo: Interdisciplinaridade

2) Objetivo

a) Geral: Compreender a importância de uma formação interdisciplinar no processo de ensino-aprendizagem do aluno.

b) Específico:

- Diferenciar os conceitos básicos para a compreensão da interdisciplinaridade;

- Entender como os conteúdos conceituais, procedimentais e atitudinais podem facilitar o aprendizado a partir de uma nova divisão do saber;

- Perceber que a interdisciplinaridade estabelece mudanças na estrutura curricular tradicional.

3) Duração: $2 \mathrm{~h}$ e $30 \mathrm{~min}$ (intervalo de $\pm 30 \mathrm{~min}$ )

4) Metodologia: Recursos e atividades

- Primeiro momento: a aula será aberta com uma discussão provocada a partir de perguntas norteadoras sobre o tema "Interdisciplinaridade". O que é interdisciplinaridade? Pra que serve? Por que usá-la como recurso (ou estratégia?) de ensino? Como preparar e aplicar uma aula interdisciplinar? Será incentivada a reflexão sobre experiências passadas e suas impressões acerca da interdisciplinaridade. (15min)

- Segundo momento: aula expositiva-dialogada sobre o tema, com apresentação de slides em powerpoint. Os pontos apresentados serão: O que é interdisciplinaridade; Qual a diferença entre termos como transdisciplinaridade, multidisciplinaridade, interdisciplinaridade e outros; o que são conteúdos conceituais, procedimentais e atitudinais e o que isso tem a ver com interdisciplinaridade; como fazer o planejamento de uma aula interdisciplinar; o diálogo entre diferentes perspectivas sobre um tema (professores e matérias); a interdisciplinaridade e a experiência do PEIC. (40min) 
- Terceiro momento: atividade prática, relacionada diretamente ao PEIC. Serão formados grupos, de preferência composta por pessoas que desejam áreas diferentes dentro do PEIC. Será feita uma breve explicação do que é uma SEMANA TEMÁTICA no PEIC, seus objetivos e finalidades. Será deixado claro que essa proposta poderá ser usada no segundo semestre do ano. Cada grupo será responsável por elaborar uma proposta de semana temática que deve conter o tema e justificativa para se abordar o tema. Além disso, deve ser feito um esboço de (sub)temas que podem ser abordados nessa semana e/ou como cada área pode abordar esse tema durante a semana, de forma a integrar todas as áreas. (50min)

- Quarto momento: Apresentação e discussão das propostas de temas para a SEMANA TEMÁTICA no PEIC com todos os participantes do curso e fechamento de ideias. (40min)

\section{5) Avaliação}

A avaliação será continuada, na interação entre professor e alunos, por meio das perguntas e respostas, principalmente durante o momento expositivodialogado. Também será avaliada a compreensão sobre o assunto com a atividade proposta no terceiro momento da aula, observando se os objetivos da atividade serão alcançados e o nível de complexidade das propostas da semana temática.

\section{6) Bibliografia}

FAZENDA, Ivani Catarina Arantes (Org.). O que é interdisciplinaridade? São Paulo: Cortez, 2008.

FRANCO, Ângela. Metodologia de Ensino. Didática. Belo Horizonte: Lê, 1997. ZABALA, Antoni. A prática educativa: Como ensinar. Porto Alegre: Artmed, 1998. 
APÊNDICE C - Plano de aula do terceiro encontro do curso de formação para novos voluntários do PEIC.

1) Assunto/Conteúdo: $O$ que é ensinar? Recursos didáticos, estratégias e abordagens de ensino.

2) Objetivo

a) Geral: Problematizar concepções prévias dos voluntários sobre "o que é ensinar?".

b) Específico

- Compreender que "o que e como ensinar" deve estar associado ao objetivo almejado com a aula, ou seja, a aprendizagem dos estudantes;

- Compreender a seleção e aplicação de recursos didáticos e estratégias de ensino como uma prática intencional;

- Conhecer as diferentes abordagens de ensino (tradicional, comportamentalista, humanista, cognitivista e socio-cultural);

- Perceber a importância de ouvir o aluno no processo de ensinoaprendizagem.

3) Duração: $2 \mathrm{~h}$ e $30 \mathrm{~min}$ (intervalo de $\pm 20 \mathrm{~min}$ )

4) Metodologia: Recursos e atividades

- Levantamento de conhecimentos prévios dos candidatos à voluntários sobre o que é ensinar (20 $\mathrm{min}$ );

- Preparação das propostas interdisciplinares. Comanda: Como posso alcançar objetivos traçados para as propostas interdisciplinares? O que é necessário para ensinar os estudantes? Escolha um objetivo específico e descreva como vocês fariam para ensiná-lo aos alunos do PEIC. Divisão dos voluntários nos três grupos formados no segundo encontro. Lápis e papel (40 min);

- Apresentação das propostas de cada grupo (20 min);

- Discussão e sistematização das diferenças entre recurso, estratégia e abordagem de ensino (30 $\mathrm{min}$ );

- Metanálise da aula: Como busquei ensinar vocês? Momento de 
discussão sobre a importância de ouvir o aluno no processo de ensinoaprendizagem. Quadro e giz (20 min);

5) Avaliação

Avaliação das aulas de interdisciplinaridade e o que é ensinar. Comanda: Vocês mudariam algo no que foi feito até agora? O que? (20 min).

6) Bibliografia

FAZENDA, Ivani Catarina Arantes (Org.). O que é interdisciplinaridade? São Paulo: Cortez, 2008.

FREIRE, Paulo. Pedagogia da autonomia. Saberes necessários à prática educativa. São Paulo: Paz e Terra, 1996.

Pedagogia do Oprimido. Rio de Janeiro: Paz e Terra, 2005.

MORIN, Edgar. Os sete Saberes Necessários à Educação do Futuro. São Paulo: Cortez; Brasília, DF: UNESCO, 2001.

MIZUKAMI, Maria da Graça Nicoletti. Ensino: as abordagens do processo. São Paulo: EPU, 1986. (Temas básicos da educação e ensino)

SKINNER, Burrhus Frederic. Sobre o behaviorismo. São Paulo: Cultrix, 1974. VYGOTSKY, Lev Semenovich. A formação social da mente. São Paulo, Martins Fontes, 1984. 
APÊNDICE D - Plano de aula do quarto encontro do curso de formação para novos voluntários do PEIC

PLANO DE AULA

1) Assunto/Conteúdo: Planejamento de aula

2) Objetivo

a) Geral: Entender aspectos práticos e teóricos concernentes ao planejamento de aula.

b) Específico:

- Refletir sobre a relevância do planejamento de aula a curto e longo prazo;

- Discutir sobre as múltiplas possibilidades na concepção dos objetivos de aula, levando em consideração a diversidade de conteúdos em diversas esferas da cognição;

- Conceber uma simulação de planejamento de aula em grupos e discutir ideias e concepções sobre os planos formados.

3) Duração: $2 \mathrm{~h}$ e $30 \mathrm{~min}$ (intervalo de $\pm 30 \mathrm{~min}$ )

4) Metodologia: Recursos e atividades

- Primeiro momento: levantamento de conhecimento prévio dos alunos a respeito do planejamento de aula. 1) Serão feitas perguntas para identificar potenciais experiências de planejamento (tentar descobrir primeiro alunos que já performaram com instrumentos musicais, teatro, danças, apresentações de seminário na escola ou na faculdade e possíveis aulas já ministradas); 2) Será solicitado a quem se manifestar que fale um pouco sobre como foi a preparação: (Como foi a preparação com relação ao público, que pontos precisaram ser revisados, como surgiu a ideia);

3) Por fim será discutido com eles pontos em comum nessas apresentações e no que elas diferem, relacionando se possível com o planejamento de uma aula. (30 min).

- Segundo momento: exposição de pontos comumente utilizados em 
planos de aula (tema, objetivos, metodologia, avaliação e bibliografia) (30 min).

- Tema e objetivos.

- Como selecionar um tema? (Necessidades e interesses dos alunos).

- O que se pretende em uma aula com determinado tema?

- Trabalhar conteúdos conceituais, atitudinais e procedimentais.

- Desenvolver seus alunos em suas carências.

- Metodologia

- Como trabalhar objetivos diversos?

- Cálculo do tempo para atividades e como elas serão realizadas pelos alunos

- Tentativas ousadas e erros (conhecimento de seus alunos).

- A avaliação

- A avaliação como ferramenta de conhecimento de seus alunos.

- O que esperar de determinada atividade

- Provas e seminários

- Bibliografia

- Terceiro momento: os voluntários serão convidados a sentarem em grupos e elaborar planos de aulas para atividades de uma semana temática discutida por eles em aula anterior (Interdisciplinaridade). Para tal, eles deverão realizá-la em forma de rascunho e chegar a um consenso no passo a passo a ser desenvolvido durante a aula (40 $\mathrm{min}$ ).

- Quarto momento: os voluntários deverão apresentar seus planos de aula abordando cada um dos passos tomados por eles, o que eles esperam, e como pretendem se avaliar (40 min).

5) Avaliação

O discurso dos alunos será uma ferramenta inicial para avaliar como eles estão integrados ao não a aula. Num momento final a forma como conduziram as discussões e como elaboraram seus planos de aulas servirão como 
amostragem para conferir se houve uma assimilação desejada dos conteúdos apresentados.

\section{6) Bibliografia}

FAZENDA, Ivani Catarina Arantes (Org.). O que é interdisciplinaridade? São Paulo: Cortez, 2008.

FRANCO, Ângela. Metodologia de Ensino. Didática. Belo Horizonte: Lê, 1997.

ZABALA, Antoni. A prática educativa: Como ensinar. Porto Alegre: Artmed, 1998. 